\title{
Tsafon
}

Revue d'études juives du Nord

$79 \mid 2020$

Les Juifs du Nord et du Pas-de-Calais dans la Shoah

\section{Birnbaum Pierre, La leçon de Vichy. Une histoire personnelle}

Danielle Delmaire

\section{(2) OpenEdition}

1 Journals

Édition électronique

URL : https://journals.openedition.org/tsafon/3028

DOI : $10.4000 /$ tsafon.3028

ISSN : 2609-6420

Éditeur

Association Jean-Marie Delmaire

Édition imprimée

Date de publication : 1 juillet 2020

Pagination : 186-187

ISSN : $1149-6630$

\section{Référence électronique}

Danielle Delmaire, «Birnbaum Pierre, La leçon de Vichy. Une histoire personnelle », Tsafon [En ligne],

79 | 2020, mis en ligne le 01 juillet 2020, consulté le 27 juin 2021. URL : http://

journals.openedition.org/tsafon/3028; DOI : https://doi.org/10.4000/tsafon.3028

Ce document a été généré automatiquement le 27 juin 2021.

Tsafon. Revues d'études juives du Nord 


\title{
Birnbaum Pierre, La leçon de Vichy. Une histoire personnelle
}

\author{
Danielle Delmaire
}

\section{RÉFÉRENCE}

Paris, Seuil, 240 p., $20 €$

1 «Théoricien de l'État fort à la française » comme le définit la quatrième page de couverture, Pierre Birnbaum livre une histoire toute personnelle, son enfance de petit juif traqué et caché pendant la guerre, dans un récit qui tient largement compte du contexte et des événements historiques et politiques qui scandent la vie chaotique des juifs entre 1940 et 1945. Ceci explique sans doute le titre : "La leçon de Vichy », d'un livre qui expose deux histoires, celle de l'auteur certes mais aussi celle du Gouvernement de Vichy dont P.B. entend redéfinir la nature, ce qu'il n'avait jamais songé à faire avant qu'il ne revisite sa petite enfance.

2 C'est son ami Pierre Assouline qui l'a incité à s'engager dans ce parcours rétrospectif. Et il le fait en tant qu'historien. Les premiers chapitres rapportent les souvenirs et la mémoire, étayés par de nombreuses recherches méticuleuses en archives (nationales, départementales, du CDJC etc.), par la lecture d'essais et de travaux universitaires tels des mémoires de maîtrise sur l'histoire régionale des Hautes-Pyrénées, département où se niche, se dissimule dans les montagnes Omex, le village où Maria et Fabien, couple de paysans, le cachèrent sans se poser de questions : «...c'est cette fois un pan de ma vie personnelle que j'expose imprudemment, c'est une plongée inattendue dans l'intime, les non-dits des cours ex cathedra, des livres et des articles des revues professionnelles », précise-t-il dès la p. 10.

3 La mémoire de son enfance se résume à Omex, non loin de Lourdes où il est né le 19 juillet 1940, en pleine déroute de la France à laquelle ses parents participent en fuyant vers le sud, vers l'Espagne proche. «Lourdes est une ville improbable pour la naissance d'un enfant juif, au terme d'un périple qui a mené mes parents dans le sud de la France 
depuis Varsovie et Dresde, en passant par Berlin», p. 20-21. Ce qui permet à la religieuse qui aide sa mère à accoucher de faire connaissance avec un bébé juif à propos duquel elle s'exclame : «Quel beau bébé, quel dommage que ce soit un Juif!» p. 21. Ce récit d'égo-histoire s'insère dans l'histoire des juifs cachés dans les Hautes-Pyrénées, ce qui invite l'auteur à fouiller les fonds d'archives pour trouver un nombre important de documents concernant ses parents. Les grandes rafles en zone libre de l'été 1942 prennent une large part dans cette évocation tant elles anéantissent, chez les juifs réfugiés dans les départements pyrénéens, l'illusion d'une région montagnarde protectrice. Et les photos personnelles viennent compléter les reproductions de documents d'archives.

4 Après avoir retrouvé Omex, où se déroula une vie heureuse, champêtre, protégée par des familles taiseuses, et les tribulations d'une famille juive; le lecteur découvre les titres des chapitres III et IV qui parlent d'eux-mêmes : "L' «État français » m'a tué » et «Les Justes m'ont sauvé ». L'ancien professeur de Paris 1 retrouve alors son écriture pour donner les leçons sur : «Le président, l'État et la théorie de l'État » et « La fin de l'alliance royale?", thèmes qui occupèrent bien des années de réflexion en sciences politiques et qui furent étudiés durant une carrière bien remplie d'universitaire. Et l'on perçoit à nouveau les critiques historiographiques sur ces sujets, abordés par un Rémond ou un Duverger, dépourvus eux d'un passé qui pouvait les sensibiliser à une démarche plus juste. Les deux derniers chapitres sont de véritables cours, des leçons, que l'on pourrait entendre dans un amphi de Sciences Po. Les démonstrations bien construites se faufilent au cours des pages et les références bibliographiques savantes ne manquent pas.

5 Ce livre est donc un savoureux mélange d'histoire mémorielle d'un enfant juif caché et d'exposé historique sur la nature de l'État en France et plus particulièrement sous le Gouvernement de Vichy. 